\title{
"Symbiotic" Hemofiltration Opens Fundamentally New Opportunities for Chronic Renal Failure Compensation
}

\author{
Yumatov EA ${ }^{1,2,3 *}$ \\ ${ }^{1}$ Department of Normal Physiology, P.K. Anokhin Research Institute of Normal Physiology, Russia \\ ${ }^{2}$ Department of Normal Physiology, Russian Academy of Sciences. I.M. Sechenov First Moscow State Medical University, Russia \\ ${ }^{3}$ Department of Normal Physiology, National Research University “Moscow Power Engineering Institute”. Moscow, Russian Federation Russia
}

Submission: February 21, 2017; Published: May 04, 2017

*Corresponding author: EA Yumatov, Department of Normal Physiology, First Moscow State Medical University, Sechenov, Institute of Higher Nervous Activity and Neurophysiology, Moscow, Russia, Email: eayumatov@mail.ru

\begin{abstract}
Summury
TWidely used nowadays hemodialysis and hemofiltration cannot replace completely the excretory function of human kidneys in natural conditions of physiological regulation. Healthy human kidneys are capable to purify patient's blood from uremic substances better than any artificial device with no doubt. Previously, we proposed a "method of "symbiotic" compensation of chronic renal failure (CRF) in humans", based on the use of healthy human kidneys natural physiological function to purge patient's blood plasma from waste substances subjected to be excreted. In the method, the clearance of blood plasma from metabolites in CRF patients is based on the temporary association of healthy human and patient's circulations. The disadvantage of this method is to mix the blood of a patient and a healthy person. Therefore, this method has certain limitations associated with the necessity of a careful partners selection with the absolute blood type compatibility.
\end{abstract}

The aim of our study is to develop and create a new method and apparatus for CRF patients "symbiotic" compensation, based on hemofiltration and healthy humans kidneys natural physiological functions, excluding mixing of partners blood. Method of "symbiotic" hemofiltration is based on mutual exchange of equivalent blood ultra filtrate volumes between healthy person and CRF patient, needed to be purified from metabolites. During exchange procedure patient's and a healthy person's circulations are separated by hemofilters excluding blood mixing.

During CRF patient's blood clearance from metabolic products separate hemofiltration of healthy donor and CRF patient in equal volumes is processed. Patient's blood ultrafiltrate enters the bloodstream of a healthy person, as a healthy person ultrafiltrate in the same extent (volume) enters the bloodstream of CRF patient. At the same time remaining after filtration blood components of donor and patient are returned in their bloodstream respectively.

Fundamentally important advantage of "symbiotic" hemofiltration is that CRF patient's blood is purged from uremic metabolites due to healthy human kidneys natural physiological functions. "Symbiotic" hemofiltration is a highly effective physiological method of CRP patient's blood purification from the uremic substances.

Keywords: Hemofiltration; Kidney; Chronic renal failure

\section{Introduction}

Clinically proven methods of chronic renal failure (CRF) compensation based on hemodialysis, hemofiltration, kidney transplantation are widely used in medical practice, but they are sometimes (15-25\%) complicated by possible water and electrolyte dysbalance in cronically treated patients [1-5].

Well known now-a-days techniques of hemodialysis and hemofiltration (Figure 1) cannot replace completely renal excretory function, which carries out all its activities in natural conditions and is regulated physiologically.

\section{Method "Symbiotic" Hemofiltration}

Previously we proposed "Method of chronic renal failure (CRF) symbiotic compensation in humans" [6, 7] is based on the use of natural physiological function of healthy human kidney for CRF patient's blood purification from waste substances subjected to be excreted. CRF patients blood purification from excessive metabolites is based on the periodic temporary association of a healthy person's and CRF patient's circulations. This method has certain limitations associated with the necessity of a careful selection of partners (donor and recipient) with an absolute blood compatibility. 


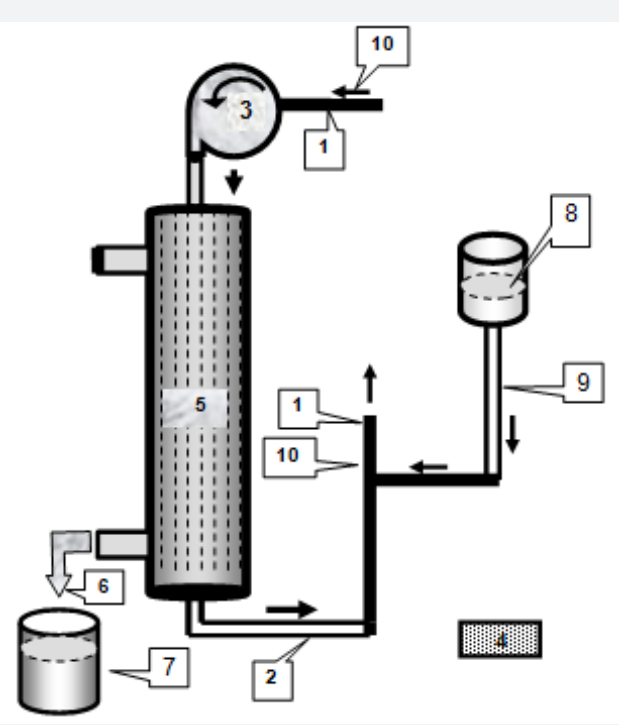

Figure 1: Scheme of device for hemofiltration with postdilyutsiey (Stetsyuk E.A. 2001).

Legend: 1 - catheters, 2- Plastic pipes, 3 - blood perfusion pumps, 4 - electronic operation and control unit, 5 - hemofilter, 6,7 - exit of the ultrafiltrate from hemofilter, 8,9 - postdilyutsiya, 10 - arrow indicating the direction of blood and fluids movement.

We have developed a completely new method and apparatus for CRF patient "symbiotic" compensation based on hemofiltration and natural physiological functions of healthy human kidneys, but exclude mixing partners circulating blood [8].

"Symbiotic" hemofiltration is based on mutual exchange of equivalent blood ultrafiltrate of healthy person and CRF patient who need blood purification from metabolites. At the same time donors and recipients blood circulatory systems are divided by hemofilter and therefore there is no blood mixing of the patient and healthy person.
During CRF patients blood purification from metabolic products separated hemofiltration of the patient's and a healthy person's blood plasma takes place in equal volumes. In this case the patient's blood ultrafiltrate flows into the bloodstream of a healthy person, and also the blood ultrafiltrate from a healthy person in the same extent enters the CRF parient's circulation. Remaining (after hemofiltration) patient's and healthy donor's blood components (formed blood elements) are returning simultaneously in their bloods circulations respectively (Figure 2).

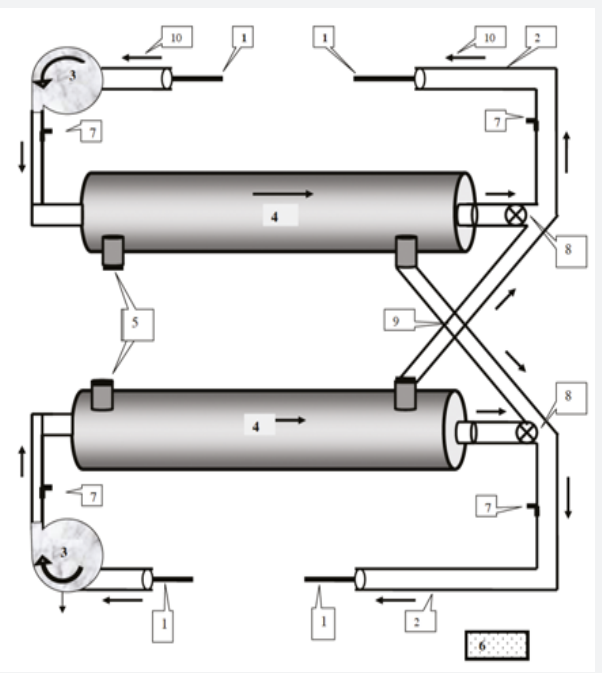

Figure 2: The device for "symbiotic" hemofiltration, which consists of two separate circuits for healthy and sick person blood circulation. Legend: 1 - catheters, 2 - Plastic pipes, 3 - blood perfusion pumps, 4 - hemofilters, 5 - plugs, 6 - electronic operation and control unit, 7 blood pressure sensors, 8 - valves, 9 - exit of the ultrafiltrate from hemofilter, 10 - arrow indicating the direction of blood and fluids movement. 
The hardware complex for "symbiotic" hemofiltration includes: blood pumps, which are used in hemodiafiltration [9], hemofilters [10], the electronic operation and control unit, pressure sensors, plastic catheter tube.

Currently, many well-known companies produce hemofilters with different characteristics [10]. Filtration characteristics of hemofilter membranes related to "high-flux" droop, are very close to the parameters of glomerular filtration rate of a healthy person's kidneys.

Mentioned hemodiafilters are designed for high-volume hemodiafiltration (HDF) with maximum pressure of $500 \mathrm{mmHg}$ and replacement volume of more than 15 liters per 1 procedure. Based on the manufacturer's data, it is possible to define the hemofilter's functional capacities and to choose the best hemofilter for procedures of "symbiotic" hemofiltration.
Calculated data for blood plasma clearance from urea and creatinine show high efficiency of "symbiotic" hemofiltration. Figure 3 shows calculated in model dynamics of urea concentrations changes in the blood of CRF patient and healthy person during a "symbiotic" hemofiltration. At the initial period of "symbiotic" hemofiltration procedure the concentration of uremic substances in healthy human blood, due to the receipt of metabolites from the patient's blood slightly increases. Kidneys of a healthy person will "respond" by increasing of their functional capacities to remove excessive wastes. With the increase of uremic metabolites in healthy person's blood plasma due to more intense glomelural clearance their concentrations will increase in primary urine and there will be an increase of their excretion with the final urine. Subsequently, fewer all uremic substances enter into healthy person's blood due to lowering of their concentration in CRF patient's blood (Figure 3).

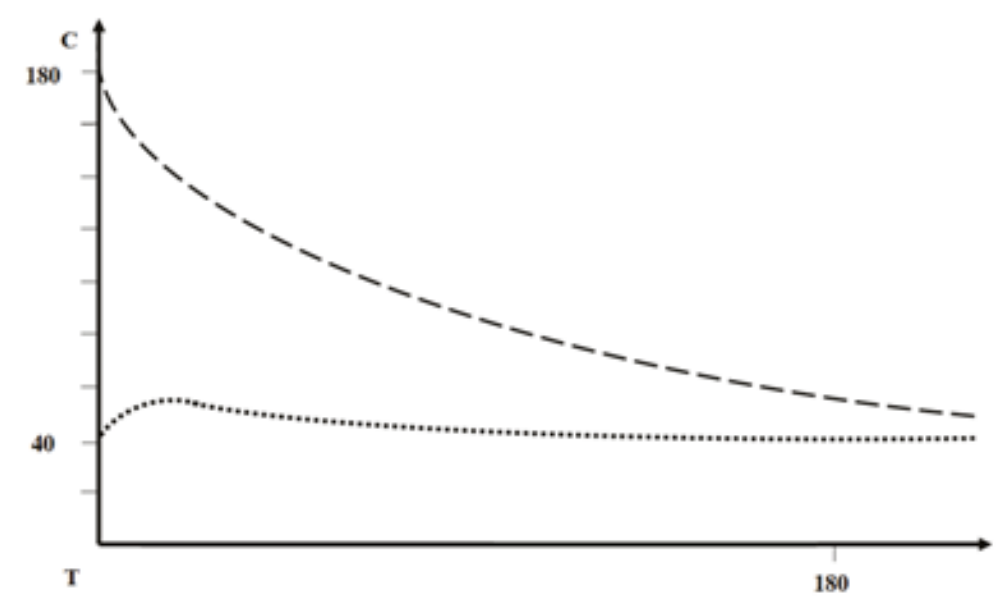

Figure 3: Urea concentration changes in healthy person's (lover curve) and in CRF patient's (upper curve) blood plasma during the procedure of "symbiotic" hemofiltration.

Legend: ordinate: $\mathrm{C}$ - the concentration of urea in the blood plasma in $\mathrm{mg} \%$, one notch - 20mg\%; abscissa axis: $\mathrm{T}$ - time (in min).

Entering into healthy person's blood of patient's urea and other nitrogenous metabolic products will not lead to an increase in their content in blood plasma, and the procedure of partners filtered blood plasma interchange does not cause any complications in healthy person.

Applied result of "symbiotic" blood plasma clearance is to reduce the level of nitrogen-containing metabolites in CRF patient's blood plasma due to more intensive physiological function of healthy partner's kidneys.

\section{Advantages of "Symbiotic" Hemofiltration over Hemodialysis and Hemofiltration}

Fundamentally important advantage of "symbiotic" hemofiltration is that the CRF patient's blood plasma clearance from uremic metabolites is produced due to the natural physiological functions of healthy human kidneys. a. Themethodis morephysiologicalthan hemodiafiltration. As a result of continuous mutual hemofiltration procedure kidneys of healthy person effectively purify CRF patient's blood plasma from uremic substances.

b. The method is less expensive, does not require expensive equipment and complex schemes of hemofiltration. There is no need to prepare and obtain a special dialysis fluid, in performing of predilution and postdilution (common practice in hemodialysis).

c. In contrast to hemofiltration, whereby it is difficult to provide an equivalent ultrafiltrate volume replacement, the method of "symbiotic" hemofiltration provides equal "cross-" ultrafiltrate exchange that maintains a constant circulating blood volume in partners circulation.

d. Due to the natural physiological function of healthy 
person's kidneys, used as a basis for patient's blood plasma clearance, the potential for complications development arising from hemodiafilration, such as acid-base dysbalance, dehydration and so forth, is reduced.

Thus, "Symbiotic" hemofiltration is highly effective method of CRF patient's blood plasma physiological purification from uremic metabolites. Nevertheless each patient and doctor has a choice - what to prefer under specific clinical settings and individual patient's comorbidities and conditions: hemodiafiltration or "symbiotic" hemofiltration for blood plasma purging from metabolites in case of decompensated chronic renal failure.

\section{References}

1. Henderson LW, Colton CK, Ford CA (1975) Kinetics of hemodiafiltration. II. Clinical characterization of a new blood cleansing modality 1975. Am Soc Nephrol 8(3): 494-508; discussion 494-500.

2. Smirnov AV (2011) Renal replacement therapy. J Nephrology 15(1): 33-46.

3. Daugirdas JT, Blake PG, Ing T S (2006) Handbook of Dialysis. ( $4^{\text {th }}$ edn),
Nephrology Dialysis Transplantation Lippincott Williams \& Wilkins, pp. 774.

4. Fomin VV, Paltseva EM, Kozlovskaya LV, Mukhin NA (2010) Nephrology. Emergency conditions. Exmo pp. 463.

5. Stetsyuk EA (2001) Fundamentals of hemodialysis. Mazo EB (Eds.), Geotar-Med, Moscow, pp. 320.

6. Yumatov EA, Sudakov KV (2012) Symbiotic "method of chronic renal failure compensating in humans. J Clinical Nephrology 5(6): 68-70.

7. Yumatov EA, Sudakov KV (2014) Method "symbiotic" compensation of chronic renal failure (CRF) in humans. Patent of Russian Federation pp. 2506956.

8. Yumatov EA, Glazachev OS, Dudnik EN, Pertsov SS, Rayevsky VV (2016) Method and device for «symbiotic» hemofiltration for compensation of chronic renal insufficiency. Journal of Inventions and Utility Models. Patent of Russian Federation pp. 2589658.

9. The pump roller for perfusion.

10. Product hemofilters: Catalogue.

11. Synthetic Dialyzer ELISIO with Polynephron Membrane

12. http://www.tehnomedservis.ru/katalog-tovarov/dializ/26-surefluxdializatori.html

Your next submission with Juniper Publishers will reach you the below assets

- Quality Editorial service

- Swift Peer Review

- Reprints availability

- E-prints Service

- Manuscript Podcast for convenient understanding

- Global attainment for your research

- Manuscript accessibility in different formats

( Pdf, E-pub, Full Text, Audio)

- Unceasing customer service

Track the below URL for one-step submission https://juniperpublishers.com/online-submission.php 